Universidade Tecnológica Federal do Paraná - UTFPR

Campus Ponta Grossa - Paraná - Brasil

ISSN: 1981-3686/ v. 08, n. 02: p. 1399-1415, 2014

D.O.I. $10.3895 / \mathrm{S} 1981-36862014000200009$
Revista Brasileira de Tecnologia

Agroindustrial

\title{
EXTRAÇÃO E CARACTERIZAÇÃO PARCIAL DE INVERTASE DE LEVEDURA DE PURÊ E RESÍDUO DE PÊSSEGO
}

\section{EXTRACTION AND PARTIAL CHARACTERIZATION OF INVERTASE OF PEACH PUREE YEAST ITS RESIDUE}

\author{
Ricardo Peraça Toralles ${ }^{1}$; Claudio Rafael Kuhn²; Priscila Silva de Sá ${ }^{3}$; Walter Augusto Ruiz ${ }^{4}$ \\ 1,2, 3 Instituto Federal Sul-Rio-Grandense - IFSUL - Pelotas - Brasil toralles@ pelotas.ifsul.edu.br \\ ${ }^{4}$ Universidade Federal do Rio Grande - FURG - Rio Grande - Brasil
}

\section{Resumo}

A frutohidrolase frutofuranosidase (EC 3.2.2.26), também chamada invertase ou sacarase, catalisa a hidrólise da sacarose, produzindo uma mistura equimolar de glicose e frutose, denominada açúcar invertido. Este produto tem alto poder edulcorante e cristalização lenta, causando um melhoramento na textura e no sabor dos alimentos. Para tal finalidade, a invertase foi extraída da levedura do purê e do resíduo de pêssego c.v. Jubileu, que é amplamente cultivada no sul do Rio Grande do Sul, Brasil. A invertase de levedura comercial de pão foi utilizada como testemunha. Os extratos enzimáticos foram obtidos usando o método de extração com bicarbonato de sódio. As condições de reação ótimas foram estudadas utilizando sacarose como substrato, a $40 \mathrm{mM}$ para a invertase de pão e a $220 \mathrm{mM}$ para a invertase de purê de pêssego. A glicose formada foi determinada por colorimetria utilizando DNS e as proteínas pelo método de Biureto. $\mathrm{O} p H$ ideal foi na faixa de 5 - 6 para ambas as enzimas. As temperaturas ótimas foram na faixa de $40-50{ }^{\circ} \mathrm{C}$ para invertase de levedura de pão e na faixa de $20-30{ }^{\circ} \mathrm{C}$ para invertase de levedura de purê de pêssego. Ambas as enzimas foram afetadas pela desnaturação de calor, sendo a invertase de pão mais termoestável. Definidas as condições ótimas de hidrólise da sacarose, estudou-se o efeito da concentração do substrato na atividade das invertases, bem como para determinar seus parâmetros cinéticos. Ambas as enzimas apresentaram comportamento Michaeliano. Os parâmetros cinéticos foram calculados por regressão não linear, sendo que os valores de $K_{m}$ foram $20 \mathrm{mM}$ e $180 \mathrm{mM}$ para a invertase de levedura de pão e para invertase de levedura de purê de pêssego, respectivamente. Para ambas, o gráfico da velocidade de hidrólise em função da concentração de sacarose foi confirmado pela linearidade da Lineweaver-Burk. Finalmente, observou-se uma equivalência entre as atividades das invertases isoladas de purê de pêssego e de seu resíduo a 25 ${ }^{\circ} \mathrm{C}$ e no $\mathrm{pH}$ de 5 .

Palavras-chave: purê de pêssego; levedura; invertase; hidrólise da sacarose; açúcar invertido.

\section{Introdução}

A produção nacional de pêssego ocupa $0,48 \%$ do volume total de frutas produzidas no país, ocupando 1\% da área plantada. Em 2010, produziu-se 239149 toneladas de pêssego, sendo os 
principais estados produtores: Rio Grande do Sul, São Paulo, Santa Catarina e Minas Gerais (FRANCHINI, 2008; SOUZA, 2008).

Segundo dados do IBGE (2010), o Rio Grande do Sul foi o maior produtor nacional, respondendo por $65 \%$ da safra de pêssego. De acordo com o Sebrae (2009), a produção da safra 2008/2009 no município de Pelotas (RS) atingiu 55.000 toneladas, 10\% superior à safra 2007/2008.

Tradicionalmente, a maior parte da produção nacional destina-se ao consumo in natura, representando cerca de 57\%. O restante é industrializado como pêssegos em calda, geleias e doces em massa, mas existe um grande potencial de crescimento de mercado na forma de purê, néctar e suco de pêssego clarificado (TORALLES et al., 2006; TORALLES e VENDRÚSCULO, 2007).

A indústria de alimentos, principalmente o ramo relacionado às frutas, gera uma grande quantidade de resíduos orgânicos ao longo de sua cadeia produtiva. Segundo Martins e Faria (2002), do total de frutas processadas são gerados na produção de sucos e polpas cerca de 30 a $40 \%$ de resíduos agroindustriais. Na produção de compotas na região de Pelotas, há uma perda na forma de resíduos de 10 a 25\% que, na maioria dos casos, são desperdiçados sem levar em consideração o valor nutricional que carregam em sua composição e, muito menos, nos compostos bioativos que se encontram majoritariamente nas cascas e sementes (TOMAS-BARBERAN, 2001; FRANCHINI, 2008; DANTAS et al., 2012; SOUSA et al., 2011).

Além de um melhor aproveitamento desses resíduos para desenvolvimento de novos produtos alimentares e, consequentemente, diminuindo a contaminação ambiental por resíduos industriais (SOUSA et al., 2011; CANTILLANO et al., 2012), alguns estudos demonstram a possibilidade da utilização de frutas e seus resíduos como fonte de extração de enzimas de interesse comercial, obtidas diretamente da polpa ou através de microrganismos nativos, como é o caso da invertase de leveduras (MORIGUI et al., 1991; MAUREL et al., 2004; RAJ et al., 2011).

Essa enzima é uma hidrolase muito utilizada na indústria de alimentos e foi a enzima que serviu de base para os estudos Michaelis-Menten relativos à curva de saturação da atividade da enzima versus substrato. A constante de Michaelis-Menten $\left(\mathrm{K}_{\mathrm{m}}\right)$, uma constante empírica igual à concentração em substrato para o qual há uma velocidade inicial igual à $\mathrm{V}_{\text {máx }} / 2$ em condições experimentais definidas, vem sendo determinada para caracterizar a hidrólise da sacarose de invertase in vitro (WHITAKER, 2003; EMREGUL, 2006; VUJČIĆ, 2011).

A invertase possui a habilidade de catalisar o desdobramento da sacarose na mistura de glicose e frutose, produzindo açúcar invertido. Embora conhecida desde o início, somente na década de 60 é que se conheceu a sua natureza química, trata-se de uma glicoproteina (CABAJ et al., 2012).

Diferente da glicose e da frutose, a sacarose é um açúcar não redutor porque a ligação glicosídica ocorre entre o carbono 1 da aldose (glicose) e o carbono 2 da cetose (frutose). Contudo, 
a hidrólise produz uma mistura de açúcares redutores a qual é mais doce que a sacarose. O nome inversão aplicada à hidrólise da sacarose foi derivado da observação da mudança na rotação ótica do açúcar (SWAISGOOD, 2003).

A hidrólise enzimática da sacarose é catalisada por dois tipos de enzimas: a $\alpha$-D-glicosidase (EC 3.2.1.20) e $\beta$-D-frutofuranosidase (EC 3.2.1.26). Embora em ambos os casos ocorra inversão, apenas a segunda delas ficou conhecida como invertina, sacarase, sucarase ou invertase, sendo este último mais comum. A atividade da invertase pode ser medida seguindo-se vários caminhos: polarimetricamente, dosagem de açúcares redutores; ou dosagem colorimétrica de glicose usando DNS (VITOLO, 1979; CANTARELLA et al., 2003).

A invertase age como catalisador na reação, resultando em uma mistura conhecida como açúcar invertido, bastante utilizado no ramo alimentício, especialmente na preparação de geleias, balas, doces e xaropes, devido ao seu alto poder edulcorante, que é cerca de $40 \%$ superior ao da sacarose, e à sua lenta cristalização, ocasionando uma melhoria na textura dos alimentos (GRACIDA, et al., 2005).

A produção do açúcar invertido também poder ser feita por catálise ácida. O problema que este tipo de catálise pode causar perda de açúcar por degradação do mesmo, levando à formação do hidroximetil furfural (HMF) com consequente desenvolvimento de cor no xarope. Isso pode ser minimizado equacionando o binômio temperatura e tempo de inversão (RODRIGUES et al., 2000).

O fator limitante para o uso da hidrólise enzimática é o elevado custo da enzima, porém um alto grau de hidrólise pode ser obtido originando um produto de alta qualidade, com baixos teores de cinzas, cor e HMF (RODRIGUES et al., 2000).

As enzimas imobilizadas têm mostrado um alto potencial como biocatalisadores em processos industriais e farmacêuticos. Elas oferecem uma vantagem distinta sobre o catalisador clássico devido a sua especificidade, alta eficiência catalítica a baixas temperaturas e, sendo biodegradável, apresentam menos problemas disponíveis. O uso de enzimas imobilizadas reduz os custos de produção podendo ser prontamente separadas do meio reacional e, consequentemente, reutilizadas (VUJČIĆ et al., 2011).

Em pêssegos, a invertase já foi caracterizada e purificada a partir de sua polpa (MORIGUCHI et al., 1991). Entre as enzimas que degradam a sacarose, a invertase ácida está amplamente difundida em frutas e vegetais, estando envolvida com o metabolismo intracelular da sacarose. A invertase é encontrada nas paredes celulares e nos compartimentos celulares na forma solúvel (BASCON et al., 2010).

As enzimas de origem microbiana têm sido bastante estudadas, especialmente as provenientes das leveduras Saccharomyces cerevisiae e Schwanniomyces occidentalis (FONTANA et al., 1992; COSTAGLIOLI et al., 1997) e dos fungos Aureobasidium sp. ATCC 20524 
(HAYASHI et al., 1992) e Aspergillus niger (ROMERO-GÓMEZ et al., 2000).

No presente trabalho existe a possibilidade da utilização da invertase não da extraída polpa de pêssego e, sim, da invertase extraída de levedura naturalmente encontrada nas frutas. Estas são importantes microhabitats para uma variedade de espécies de leveduras devido a sua favorável concentração de açúcar e ao seu pH. As leveduras encontram-se presentes principalmente nas frutas maduras e apodrecidas devido à visitação de insetos vetores. A Drosophila está entre os mais importantes (SANTOS et al., 1996; HOFFMANN et al., 1997). A cultivar de pêssego escolhida foi a Jubileu porque é produtiva e amplamente cultivada na região sul. Além disso, apresenta características sensoriais favoráveis para elaboração de purê de pêssego. (TORALLES et al., 2006; EMBRAPA 2012; LOPES, 2013). Assim, conduziu-se um estudo experimental para analisar a influência do $\mathrm{pH}$, temperatura e concentração de sacarose na atividade da invertase extraída da levedura do purê de pêssego e seu resíduo, utilizando a invertase de levedura comercial como testemunha.

\section{Material e Métodos}

\section{Micro-organismos e cultivo}

Os micro-organismos usados nesta investigação foram isolados a partir de purê de pêssego da cultivar Jubileu concentrado até $22{ }^{\circ}$ Brix e armazenado a $-20{ }^{\circ} \mathrm{C}$, sendo produzido na planta piloto do Instituto Federal Sul Riograndense-IFSUL campus Visconde da Graça, como descrito por Toralles e Vendrúsculo (2007). A contagem foi feita como descrito por Siqueira (1995) para bolores e leveduras. Obteve-se uma contagem inicial total de $22 \times 10^{2}$ UFC.mL $\mathrm{mL}^{-1}$ após 5 dias de estocagem $25{ }^{\circ} \mathrm{C}$, usando batata dextrose ágar (BDA, Biolife italiana) em $\mathrm{pH}$ 5. As culturas estoque foram mantidas a $4{ }^{\circ} \mathrm{C}$. Neste $\mathrm{pH}$ foi que se observou um crecimento favorável de leveduras em detrimento de fungos (Figura 1).

As culturas de leveduras foram cultivadas em frascos Erlenmeyer em $1000 \mathrm{~mL}$ de meio a $150 \mathrm{rpm}$, a $30^{\circ} \mathrm{C}$, pH 5 por 24 horas. O meio continha 20 g.L $\mathrm{L}^{-1}$ de cultura estoque em BDA, 20 g.L $\mathrm{L}^{-1}$ de glicose, $\left(\mathrm{NH}_{4}\right)_{2} \mathrm{SO}_{4} 1$ g.L $\mathrm{L}^{-1} ; \mathrm{KH}_{2} \mathrm{PO}_{4} 2$ g.L $\mathrm{L}^{-1} ; \mathrm{MgSO}_{4} .7 \mathrm{H}_{2} \mathrm{O}$ 0,5 g.L $\mathrm{L}^{-1} ; \mathrm{FeSO}_{4}$ 0,5 g.L $\mathrm{L}^{-1}$ e peptona 5 g.L $\mathrm{L}^{-1}$. Após, uma nova semeadura foi realizada para purificar as leveduras. Nesta suspensão, a contagem total final foi cerca de $10^{9} \mathrm{UFC} \cdot \mathrm{mL}^{-1}$. As culturas foram mantidas a $4{ }^{\circ} \mathrm{C}$ e reativadas a cada 30 dias. O mesmo procedimento utilizou-se para o isolamento de levedura do resíduo de pêssego c.v. Jubileu. 
Figura 1 - Placa com colônias típicas de leveduras

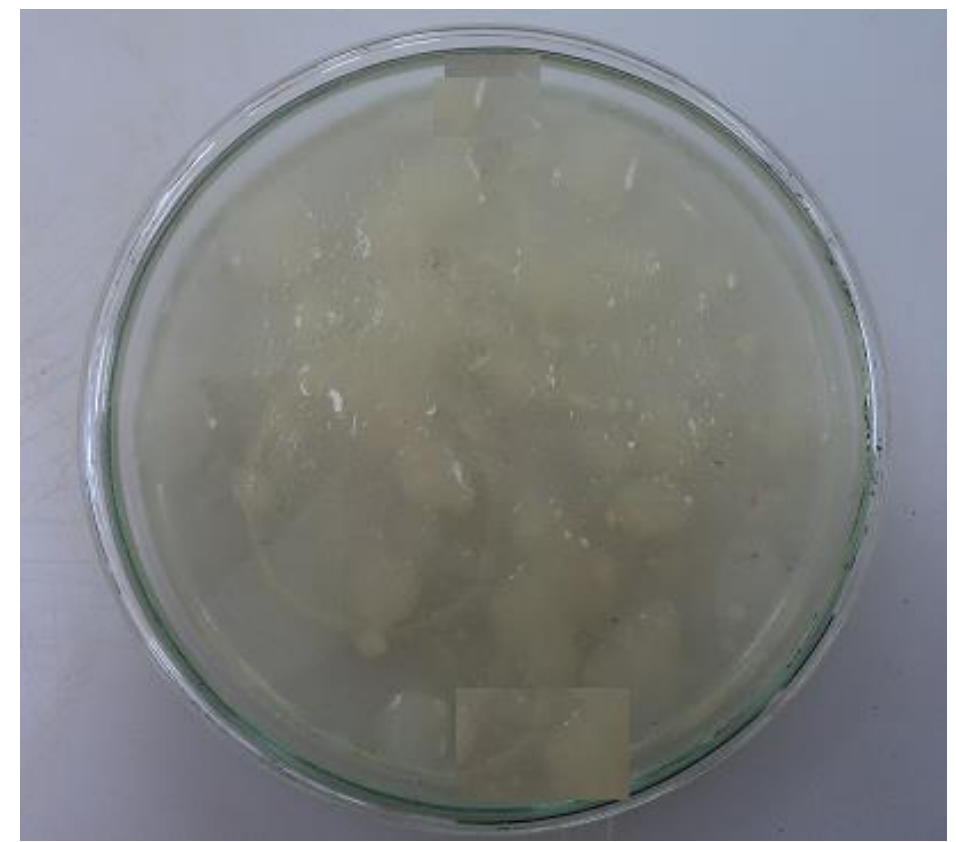

\section{Extração das invertases}

Para a invertase de levedura comercial, foram pesados 100 gramas de levedura de pão e adicionados $300 \mathrm{~mL}$ de $\mathrm{NaHCO}_{3} 0,10 \mathrm{M}$, deixando-se em banho-maria a uma temperatura de 40 a $50{ }^{\circ} \mathrm{C}$ por 24 horas sob agitação. $\mathrm{O}$ extrato enzimático $\left(\mathrm{E}_{1}\right)$ consistiu no sobrenadante resultante da centrifugação a 5000xg por 5 minutos, sendo armazenado a $-20{ }^{\circ} \mathrm{C}$. No extrato centrifugado foi determinado o teor de proteínas por Biureto, utilizando BSA como padrão (Acros, New Jersey, USA).

Para a invertase de levedura de purê de pêssego e do seu resíduo, foram pesados $100 \mathrm{~g}$ da composição da placa de cultivo da levedura com BDA, seguindo-se os mesmos procedimentos utilizados para extração da invertase de levedura comercial.

\section{Determinação colorimétrica da glicose}

A glicose, na faixa de concentração de 0 a 500 ppm, foi utilizada para construir uma curva padrão. Alíquotas de 1,0 mL de cada solução padrão adicionou-se $1,0 \mathrm{~mL}$ de água destilada e 1,0 mL de reagente ácido 3,5-dinitrosalicilico (DNS, Sigma Aldrich Chemie GmbH, Alemanha). Após 10 minutos do meio reativo em banho-maria a $25^{\circ} \mathrm{C}$, adicionou-se $1,0 \mathrm{~mL}$ de reativo DNS seguido de banho-maria fervente por 5 minutos, adicionando-se, após o resfriamento a temperatura ambiente, 7,0 mL de água destilada, sendo feita a leitura em espectrofotômetro UV/VIS a $490 \mathrm{~nm}$. A massa de glicose no meio reativo, em $\mu$ g, foi determinada através da Equação 1:

$$
\mathrm{m} \text { glicose }=\frac{(A A-A B)+B}{A} \times \mathrm{V} \times \mathrm{F}
$$


onde $A B$ é a absorbância do branco, $A A$ é a absorbância da amostra, $B$ é o coeficiente linear da reta, $A$ é a constante de proporcionalidade; $V$ é o volume final do meio reativo, em $\mathrm{mL}$, e $F$ é o fator de diluição. O valores de A e B encontram-se determinados em Resultados e Discussão (item 3.1).

\section{Estudo da atividade da invertase}

A atividade enzimática da invertase foi determinada por estimativa colorimétrica da glicose usando reagente DNS. A transmitância resultante dessa reação foi medida a $490 \mathrm{~nm}$, utilizando um espectrofotômetro Varian UV/VIS.

Para a invertase de levedura isolada de purê de pêssego e de seu resíduo, o meio reacional continha 1,0 mL de tampão Mcllvaine; 1,0 mL de solução de sacarose como substrato e 1,0 mL de extrato enzimático. A mistura reativa final continha $220 \mathrm{mM}$. Para a invertase de levedura de pão (testemunha) usou-se as mesmas quantidades, mas $40 \mathrm{mM}$ de concentração final de sacarose no meio reacional. A reação foi conduzida em diferentes concentrações de extrato enzimático, pHs e temperaturas. Após, foi dosado o teor de glicose.

No branco, foi utilizado $1,0 \mathrm{~mL}$ de água deionizada em substituição ao substrato na mistura reativa. A atividade enzimática foi calculada na parte linear da curva. Uma unidade de atividade foi definida como a quantidade de enzima que causa o incremento de $1 \mu \mathrm{g}$ glicose. $\min ^{-1}$.

\section{Efeito do pH e temperatura}

$\mathrm{O}$ efeito do $\mathrm{pH}$ na atividade da invertase foi determinado a $25{ }^{\circ} \mathrm{C}$, na faixa de $\mathrm{pH}$ entre 3 e 8 , usando tampão Mcllvaine apropriado. $\mathrm{O}$ pH ótimo foi utilizado em todos outros experimentos. Para estudar o efeito da temperatura, a atividade foi determinada entre 10 e $70{ }^{\circ} \mathrm{C}$, usando banho termostatizado e circulante, Thermo Haake $\mathrm{C} 10$. O meio reativo e o extrato enzimático foram préaquecidos separadamente por 1 minuto, em tubos com tampa (d.i 9mm, parede 1mm), na temperatura testada e, então, a enzima foi adicionada.

\section{Efeito da concentração de substrato}

A sacarose, em várias concentrações, foi utilizada como substrato para ambas as invertases. Para a de levedura de pêssego c.v. Jubileu, a concentração variou entre 0 e $500 \mathrm{mM}$ nas condições ótimas de $\mathrm{pH}$ e temperatura de $25^{\circ} \mathrm{C}$. Para a levedura de pão, variou entre 0 e $140 \mathrm{mM}$ de sacarose. A constante de Michaelis-Menten $\left(\mathrm{K}_{\mathrm{m}}\right)$ e velocidade máxima $\left(\mathrm{V}_{\text {máx }}\right)$ foram determinadas por regressão não linear. O comportamento linear dos dados foi investigado por Lineweaver e Burk (1934).

\section{Análise estatística}

Os testes foram realizados em triplicata, para obtenção das médias e desvios padrão. O 
Software Statistica foi utilizado para calcular os coeficientes de regressão não linear, coeficiente de determinação e análise de variância (ANOVA). Os intervalos de confiança dos coeficientes foram calculados multiplicando o erro padrão por Student- $\left.\mathrm{t}_{\left(\mathrm{n}_{\mathrm{n}}\right)}\right)$, ajustado aos graus de liberdade $(\mathrm{p}=$ $0,05)$.

\section{Resultados e Discussão}

\section{Curva Padrão da dosagem de glicose usando DNS}

As concentrações de glicose foram determinadas a partir da Figura 2 - curva padrão da glicose usando DNS. A constante de proporcionalidade (A) entre a absorbância e a concentração de glicose e coeficiente linear da reta (B) foram calculadas por regressão linear (Tabela 1). Os valores de A e B foram ambos significativos $(\mathrm{p} \leq 0,01)$ sendo, respectivamente, A igual 1,57 e B igual a 0,15. Os Limites de Detecção (LD) e Quantificação (LQ) iguais a 181,2 mg.mL ${ }^{-1}$ e 356,2 mg.mL $\mathrm{mL}^{-1}$.

Tabela 1 - Parâmetros A e B da curva padrão de dosagem de glicose em DNS e de dosagem de proteínas em Biureto

\begin{tabular}{cc}
\hline Parâmetros & Valores $^{\text {a }}$ \\
\hline $\mathrm{A}\left(\mathrm{L} \cdot \mathrm{g}^{-1} \cdot \mathrm{cm}^{-1}\right)$ & $1,57 \pm 0,088^{* *}$ \\
$\mathrm{~B}$ & $-0,15 \pm 0,029^{* *}$ \\
$\mathrm{R}^{2}$ & 0,9991 \\
\hline
\end{tabular}

valor \pm intervalo de confidência a $\mathrm{p}=0.05 . * *$ Significativo $(\mathrm{p} \leq 0,01)$. ns Não significativo

Figura 2 - Curva padrão de glicose

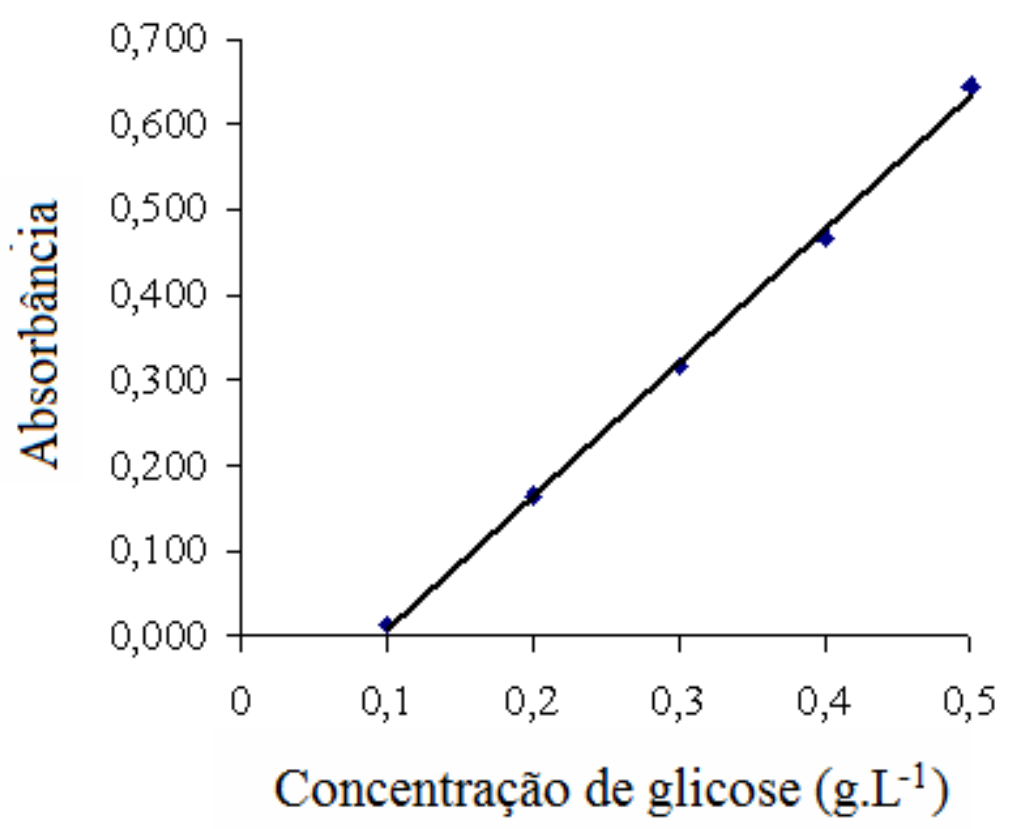

Na Tabela 2, têm-se os resultados para o teor de proteína. Para invertase de levedura de pão, 
o teor de proteínas foi de 4,97 $( \pm 0,70) \mathrm{mg} \cdot \mathrm{mL}^{-1}$, no extrato enzimático na diluição $10^{-1}$, sendo que os extratos nas diluições $10^{-2}$ e $10^{-3}$ não obtiveram resultados detectáveis, apresentando valores inferiores ao Limite de Detecção. Para a invertase de levedura de pêssego, obteve-se 4,35 $( \pm 0,12)$ mg. $\mathrm{mL}^{-1}$ como teor de proteína, referente ao extrato bruto, com limites não detectáveis a partir da diluição $10^{-1}$ do extrato enzimático. Para invertase de resíduo de pêssego encontrou-se $4,15( \pm 0,10)$ somente para $\mathrm{E}_{1}$. Para o estudo do efeito do $\mathrm{pH}$, temperatura e concentração de substrato utilizaramse, respectivamente, as diluições $10^{-1}$ e $E_{1}$ na definição da atividade da invertase de levedura de pão e pêssego.

Tabela 2 - Teor de proteína nos extratos de invertase de levedura de pão, de levedura do purê de pêssego e seu resíduo.

\begin{tabular}{cccc}
\hline & \multicolumn{3}{c}{ Teor de proteína (mg.mL $^{\mathbf{- 1}}$ ) } \\
\hline Extrato enzimático $^{\mathbf{a}}$ & \multicolumn{3}{c}{ Invertase de levedura } \\
\hline & Pão & Purê de pêssego & Resíduo de pêssego \\
\hline $\mathrm{E}_{1}$ & $52,71 \pm 1,31$ & $4,35 \pm 0,12$ & $4,15 \pm 0,10$ \\
$\mathrm{E}_{1} / 2$ & $29,89 \pm 3,75$ & $2,13 \pm 0,02$ & - \\
$10^{-1}$ & $4,97 \pm 0,70$ & - & - \\
$10^{-2}$ & - & - & - \\
$10^{-3}$ & - & - & - \\
\hline
\end{tabular}

a $\mathrm{E}_{1}$ : extrato enzimático centrifugado preparado como descrito no item 2.4; $\mathrm{E}_{1} / 2$ : extrato enzimático diluído pela metade com água; o 10-1: extrato diluído com água destilada na proporção 1:10 e, assim, sucessivamente.

\section{Efeito do $\mathrm{pH}$}

Os resultados do efeito do $\mathrm{pH}$ nas atividades das invertases de levedura de pão e de levedura de pêssego, a $40 \mathrm{mM}$ e $220 \mathrm{mM}$, respectivamente, a $25{ }^{\circ} \mathrm{C}$, mostram-se na Tabela 3. Para a atividade da invertase extraída da levedura de pão, os valores $17,27 \mathrm{U}_{\mathrm{mg}}{ }^{-1}\left(\mathrm{pH}\right.$ 5) e 17,30 U.mg ${ }^{-1}$ ( $\mathrm{pH}$ 6) foram superiores aos demais, não diferindo estatisticamente entre si $(\mathrm{p}<0,05)$. Enquanto que, para a invertase de purê de pêssego, os maiores valores foram 8,86 U.mg ${ }^{-1}(\mathrm{pH}$ 5) e 8,21 U.mg-1 $(\mathrm{pH}$ 6), seguido de 7,83 U.mg ${ }^{-1}$ em $\mathrm{pH}$ 4. Para invertase isolada de resíduo de pêssego, em pH 5 a 25 ${ }^{\circ} \mathrm{C}$, encontrou-se 8,35 U.mg-1 . Nas demais condições não foram feitos estudos com esta invertase porque se acredita que se trata da mesma invertase extraída da levedura do purê de pêssego.

Tabela 3 - Efeito do pH na atividade da invertase

\begin{tabular}{ccc}
\hline pH & \multicolumn{2}{c}{ Invertase de levedura } \\
\hline 3 & $\begin{array}{c}\text { Pão } \\
\left(\mathrm{U}^{-1} \mathrm{mg}^{-1}\right)\end{array}$ & $\begin{array}{c}\text { Purê de pêssego } \\
\left(\mathrm{U}_{\mathrm{mg}}^{-1}\right)\end{array}$ \\
\hline 4 & $6,80 \pm 0,84 \mathrm{c}$ & $6,72 \pm 0,57 \mathrm{~b}$ \\
5 & $15,67 \pm 0,89 \mathrm{ab}$ & $7,83 \pm 0,26 \mathrm{ab}$ \\
6 & $17,27 \pm 1,95 \mathrm{a}$ & $8,86 \pm 0,24 \mathrm{a}$ \\
7 & $17,30 \pm 1,08 \mathrm{a}$ & $8,21 \pm 0,59 \mathrm{a}$ \\
8 & $13,20 \pm 0,76 \mathrm{~b}$ & $7,39 \pm 0,93 \mathrm{ab}$ \\
\hline
\end{tabular}

A Figura 3 foi construída a partir dos dados experimentais da Tabela 3. A máxima atividade específica de 17,30 $( \pm 1,08)$ tomou-se com $100 \%$ de atividade relativa (AR\%) para invertase de 
levedura de pão. Quando comparado com essa atividade, a invertase de levedura de purê de pêssego mostrou cerca de 50\% desse valor. Para ambas as enzimas, o pH ótimo ficou na faixa de 5-6. Resultados semelhantes foram encontrados para as invertases da levedura comercial (BARBOSA, 2009; SANTOS 2010), bem como para invertase comercial livre e imobilizada (BORA et al., 2005).

A dependência do pH é uma importante característica tecnológica para produção de açúcar invertido, pois tal dependência afeta a ionização dos resíduos de aminoácidos essenciais que estão envolvidos na ligação do substrato e sua transformação em produto (NOVAKI, 2009).

Figura 3 - Efeito do pH na atividade da invertase de levedura de pão $(\bullet)$ e de purê de pêssego (•). Substrato: solução de sacarose $40 \mathrm{mM}$ e $220 \mathrm{mM}$ na concentração final do meio reacional, respectivamente. Tampão: Mcllvaine (3-8).

Temperatura: $25 \pm 0,1^{\circ} \mathrm{C}$. Enzima: $1,0 \mathrm{~mL}$ de extrato enzimático em 3,0 $\mathrm{mL}$ de meio reativo

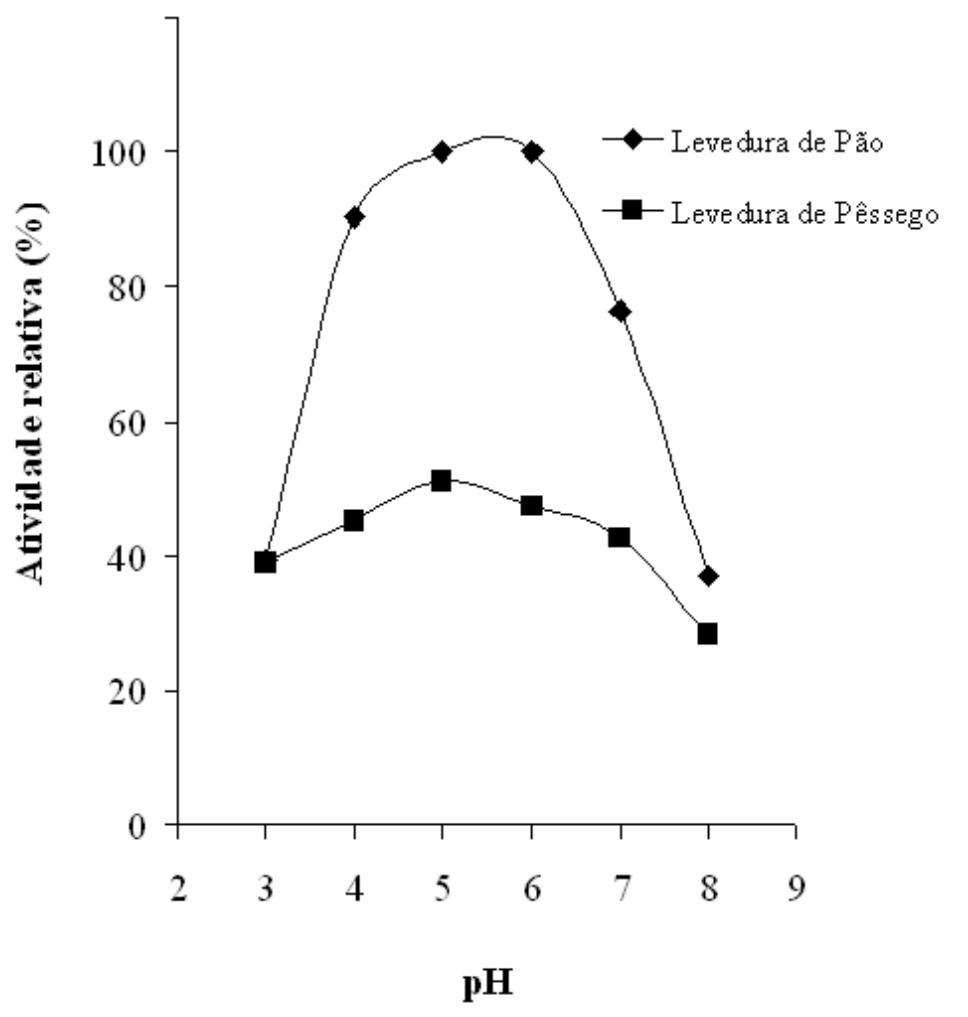

\section{Efeito da temperatura}

Os resultados do efeito da temperatura nas atividades das invertases de levedura de pão e de levedura de purê de pêssego, a $40 \mathrm{mM}$ e $220 \mathrm{mM}$, respectivamente, em pH 5, mostram-se na Tabela 4.

Tabela 4 - Efeito da temperatura na atividade da invertase

\begin{tabular}{ccc}
\hline $\begin{array}{c}\text { Tratamento } \\
\left({ }^{\circ} \mathrm{C}\right)\end{array}$ & $\begin{array}{c}\text { Pão } \\
\left(\mathrm{U}_{\mathrm{mg}}{ }^{-1}\right)\end{array}$ & $\begin{array}{c}\text { Invertase de levedura } \\
\text { Purê de pêssego } \\
\left(\mathrm{U} . \mathrm{mg}^{1}\right)\end{array}$ \\
\hline 10 & $2,28 \pm 0,31 \mathrm{f}$ & $4,77 \pm 1,33 \mathrm{abc}$ \\
20 & $12,53 \pm 1,66 \mathrm{~d}$ & $8,44 \pm 0,92 \mathrm{a}$ \\
30 & $20,73 \pm 0,80 \mathrm{~b}$ & $8,29 \pm 1,62 \mathrm{a}$ \\
40 & $30,04 \pm 0,56 \mathrm{a}$ & $7,41 \pm 2,02 \mathrm{ab}$ \\
50 & $31,91 \pm 1,23 \mathrm{a}$ & $4,01 \pm 1,61 \mathrm{bc}$ \\
60 & $17,27 \pm 1,11 \mathrm{c}$ & $3,02 \pm 1,12 \mathrm{c}$ \\
70 & $7,40 \pm 1,09 \mathrm{e}$ & $3,78 \pm 1,06 \mathrm{bc}$ \\
\hline
\end{tabular}

Valores médios com diferentes letras são significativos a $\mathrm{p} \leq 0,05$ 
Para a atividade da invertase extraída da levedura de pão, os valores $30,04 \mathrm{U} \cdot \mathrm{mg}^{-1}\left(40{ }^{\circ} \mathrm{C}\right) \mathrm{e}$ $31,91 \mathrm{U} \cdot \mathrm{mg}^{-1}\left(50{ }^{\circ} \mathrm{C}\right)$ foram superiores aos demais, não diferindo estatisticamente entre si $(\mathrm{p}<0,05)$. Enquanto que, para a invertase de purê de pêssego, os maiores valores foram $8,44 \mathrm{U}_{\mathrm{mg}} \mathrm{m}^{-1}\left(20^{\circ} \mathrm{C}\right) \mathrm{e}$ 8,29 U.mg-1 $\left(30{ }^{\circ} \mathrm{C}\right)$, seguido de 7,41 U.mg ${ }^{-1}$ a $40{ }^{\circ} \mathrm{C}$.

A Figura 4 foi construída a partir dos dados experimentais da Tabela 4. Para a invertase de pão, a máxima atividade específica de $31,91( \pm 1,23) \mathrm{U} \cdot \mathrm{mg}^{-1}$ a $50{ }^{\circ} \mathrm{C}$ foi tomada como $100 \%$ de atividade relativa (AR\%). Quando comparado com essa atividade, a invertase de levedura de pêssego mostrou cerca de $25 \%$ deste valor entre 20 e $30^{\circ} \mathrm{C}$.

Nessa mesma figura, notou-se um efeito antagônico na atividade de ambas as invertases: de um lado até o ponto de ótimo, observou-se um aumento da atividade com a elevação da temperatura; de outro, um comportamento contrário. A melhor explicação para esse efeito é que a partir do ponto ótimo começa a desnaturação da proteína da enzima (WHITAKER, 2003). Trabalhos atuais apontam que a perda do sítio ativo precede a desnaturação (DANIEL et al., 2010). Além disso, os resultados mostram que a invertase de levedura de pão é mais termoestável do que a invertase de levedura de pêssego. Para quatro isoformas de invertase de S. cerevisiae, Andjelković et al. (2010) observaram uma ótima temperatura de $60^{\circ} \mathrm{C}$, que é superior ao encontrado para invertase de levedura de pão. Novaki (2009), trabalhando com invertase do fungo Aspergillus casiellus, também observou um valor superior de $70{ }^{\circ} \mathrm{C}$.

Figura 4 - Efeito da temperatura na atividade da invertase de levedura de pão $(\bullet)$ e de purê de pêssego $(\bullet)$. Substrato: solução de sacarose $40 \mathrm{mM}$ e $220 \mathrm{mM}$ na concentração final do meio reacional, respectivamente. Tampão Mcllvaine: pH de 5. Enzima: 1,0 mL de extrato enzimátco em 3,0 $\mathrm{mL}$ de meio reativo.

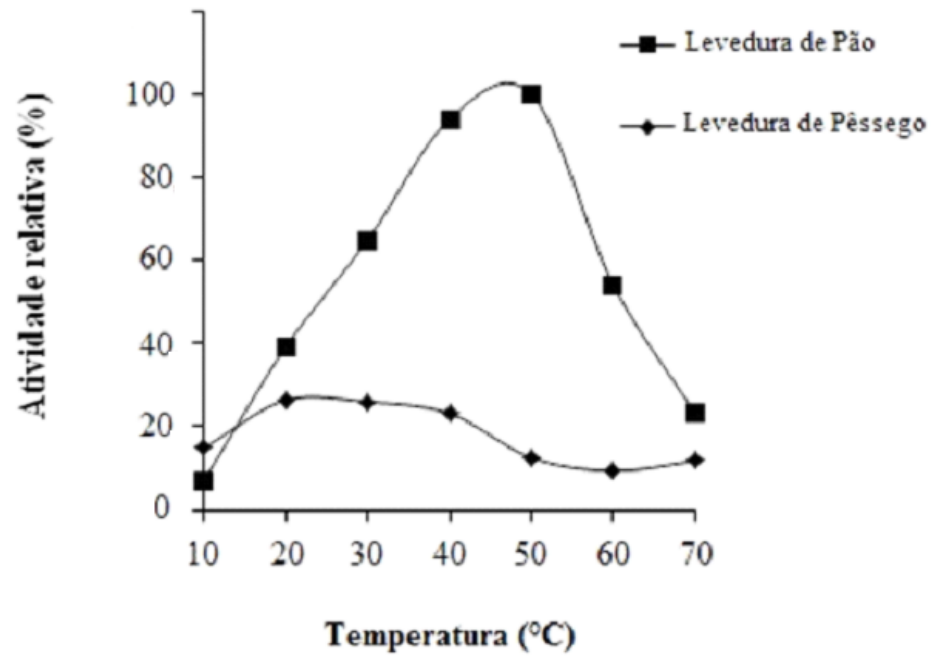

\section{Parâmetros cinéticos}

Os parâmetros cinéticos para a velocidade de inversão da sacarose foram determinados para 
invertase de levedura de pão e para invertase de levedura de pêssego. Para invertase de levedura de pão, o gráfico da velocidade ( $\mathrm{U}$ mg proteina $\left.{ }^{-1}\right)$ versus a concentração de sacarose $\left(\mathrm{mmol} . \mathrm{L}^{-1}\right)$ foi hiperbólico, sugerindo a cinética de Michaelis-Menten (Figura 5). Os pontos experimentais foram confirmados pela linearidade do gráfico de Lineweaver-Burk (Figura 5, inserção). O valor de $\mathrm{K}_{\mathrm{m}}$, encontrado por regressão não linear, foi cerca de $24 \mathrm{mM}$ sacarose, que é muito próximo ao encontrado por Andjelković et al. (2010), para quatro isoformas de invertase de S. cerevisiae. Guimarães et al. (2007), trabalhando com invertase de Aspergillus ochraceus, encontraram um $\mathrm{K}_{\mathrm{m}}$ de 13,4 mM de sacarose, $V_{\text {máx }}$ de 42,13 U.mg ${ }^{-1}$ e um valor $V_{\text {máx }} / K_{m}$ de cerca de 3 U.mg ${ }^{-1} \cdot \mathrm{mM}^{-1}$. Tal valor é chamado de coeficiente de especificidade e, para invertase de levedura de pão foi cerca de 2. Isso sugere que esta tem menor especificidade pela sacarose que aquela. A $50{ }^{\circ} \mathrm{C}$ e pH 5, Santos (2010), trabalhando com a mesma levedura comercial de pão, encontrou um $\mathrm{K}_{\mathrm{m}}$ de $132,0 \mathrm{mM}$ e $\mathrm{V}_{\text {máx }}$ de 164,0 U.mg ${ }^{-1}$. Tal fato mostra que a constante cinética de Michaelis-Menten é dependente da temperatura.

Figura 5 - Efeito da concentração de sacarose na velocidade da invertase de levedura de pão. Tampão Mcllvaine: pH de 5. Temperatura: $25 \pm 0,1^{\circ} \mathrm{C}$. Enzima: $1,0 \mathrm{~mL} \mathrm{em} 3,0 \mathrm{~mL}$ de meio reativo. Inserção: gráfico de Lineweaver-Burk.

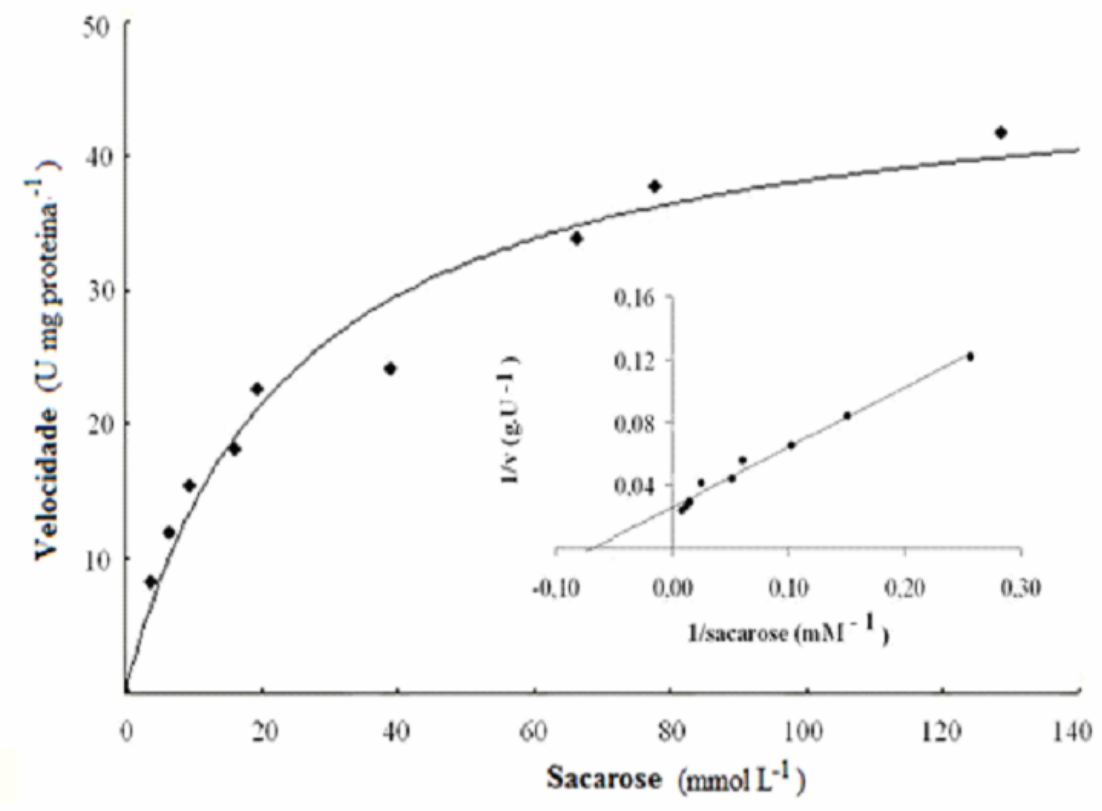

Para invertase de levedura de purê de pêssego, também se observou um comportamento Michaeliano da enzima a partir de $100 \mathrm{mM}$ (Figura 6). Antes dessa concentração, praticamente a atividade se manteve constante. O valor de $\mathrm{K}_{\mathrm{m}}$ encontrado foi cerca de $180 \mathrm{mM}$ de sacarose com

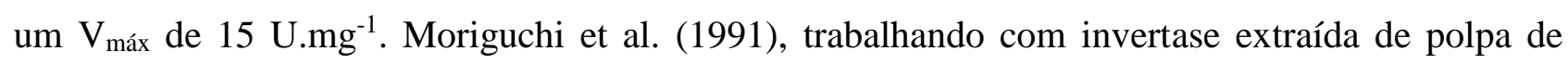
pêssego, encontraram um $\mathrm{K}_{\mathrm{m}}$ de 4,2 $\mathrm{mM}$ de sacarose e $14,2 \mathrm{mM}$ de rafinose em $\mathrm{pH}$ de 5 . Tal fato mostra que a invertase da polpa de pêssego tem maior afinidade do que a extraída da sua levedura. 
Por outro lado, o alto valor da constante de Michaelis-Menten encontrado neste trabalho não é um fato isolado para invertases extraídas de leveduras livres ou imobilizadas. Emregul et al. (2006) encontraram $86 \mathrm{mM}$ e $166 \mathrm{mM}$ para invertase comercial livre e imobilizada, respectivamente. Eles alegaram que o aumento de cerca de 1,92 no valor de $\mathrm{K}_{\mathrm{m}}$ pode ser devido ao limitado acesso das moléculas de sacarose ao sítio ativo da enzima imobilizada. Tal fato pode ser a sua distribuição ao longo da camada do polímero utilizado para imobilização e sua modificação conformacional. Neste trabalho, acredita-se que a invertase pode ter ficado imobilizado em BDA porque a extração foi feita a partir das leveduras contidas nas placas. Uma purificação do extrato enzimático usando a extração com acetona, precipitação com $\left(\mathrm{NH}_{4}\right)_{2} \mathrm{SO}_{4}$ seguido de diálise, deve resultar em menores valores de $\mathrm{K}_{\mathrm{m}}$. Estamos trabalhando com a purificação do extrato enzimático para responder tal questão.

Figura 6 - Efeito da concentração de sacarose na velocidade da invertase de levedura de purê de pêssego. Tampão Mcllvaine: $\mathrm{pH}$ 5. Temperatura: $25 \pm 0,1^{\circ} \mathrm{C}$. Enzima: $1,0 \mathrm{~mL}$ em 3,0 $\mathrm{mL}$ de meio reativo. Inserção: gráfico de Lineweaver-Burk

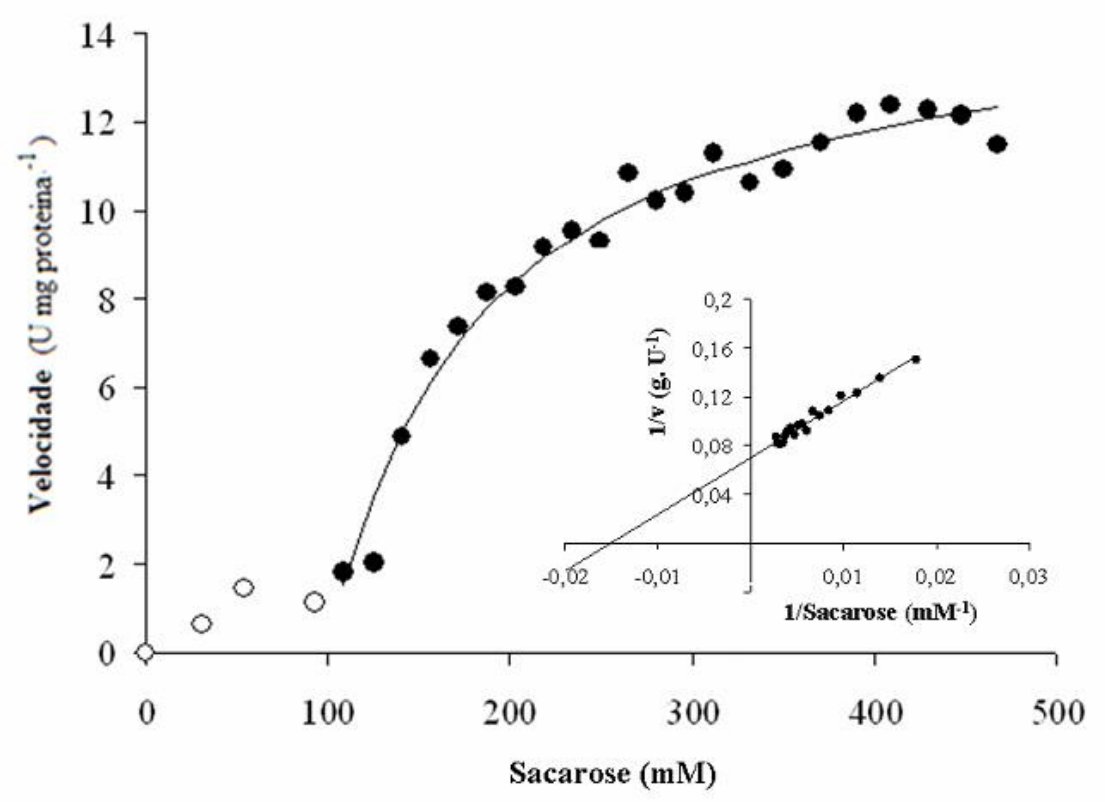

Os parâmetros cinéticos para velocidade foram calculados por regressão não linear (Tabela 5).

Tabela 5 - Constante de Michaelis $\left(\mathrm{K}_{\mathrm{m}}\right)$ e velocidade máxima $\left(\mathrm{V}_{\mathrm{máx}}\right)$ da invertase de levedura comercial e de levedura de purê de pêsego da cultivar Jubileu

\begin{tabular}{|c|c|c|}
\hline \multirow[t]{2}{*}{ Parâmetro } & \multicolumn{2}{|c|}{ Valor } \\
\hline & Levedura de pão $^{a}$ & Levedura de pêssego \\
\hline $\mathrm{K}_{\mathrm{m}, \text { ap }}{ }^{\mathrm{a}}(\mathrm{mM})$ & $23,98 \pm 3,25 * *$ & $180,46 \pm 10,86 * *$ \\
\hline $\mathrm{V}_{\text {máx }}{ }^{\mathrm{a}}\left(\mathrm{U} \cdot \mathrm{mg}^{-1}\right)$ & $47,31 \pm 2,25 * *$ & $14,99 \pm 7,51 * *$ \\
\hline $\mathrm{V}_{\text {máx }} / \mathrm{K}_{\mathrm{m}}\left(\mathrm{U} \cdot \mathrm{mg}^{-1} \cdot \mathrm{mM}^{-1}\right)$ & 1,97 & 0,18 \\
\hline $\mathrm{R}^{2}$ & 0,97 & 0,972 \\
\hline
\end{tabular}

${ }^{\mathrm{a}}$ valor \pm intervalo de confidência a $\mathrm{p}=0.05 .{ }^{* *}$ Significativo $(\mathrm{p} \leq 0,01) .{ }^{\text {ns }}$ Não significativo 
Devido à purificação parcial do extrato enzimático, utilizou-se a constante aparente de Michaelis $\left(\mathrm{K}_{\mathrm{m}, \mathrm{ap}}\right)$. O modelo de Michaelis-Menten foi estatisticamente significativo $(\mathrm{p} \leq 0,01)$ para descrever a atividade da invertase em ambos os casos, porque o valor de F calculado foi 26 e 83 vezes maior do que o valor listado, respectivamente para invertase de levedura de pão e para levedura de purê pêssego (Tabela 6). Como regra prática, um modelo tem significação estatística quando o valor de F calculado é pelo menos 3-5 vezes maior do que o valor listado (GACULA e SINGH, 1984).

\section{Conclusão}

Tanto a invertase de levedura de pão quanto a invertase de levedura de purê de pêssego desenvolveram ótima atividade em $\mathrm{pH}$ na faixa 5 - 6, mas diferiram quanto a faixa de temperatura ótima que foram, respectivamente, $40-50^{\circ} \mathrm{C}$ e $20-30^{\circ} \mathrm{C}$. O tratamento térmico foi efetivo para reduzir significativamente a atividade acima de $60^{\circ} \mathrm{C}$ para invertase de levedura de pão, que mostrou-se mais termoestável do que invertase de levedura de purê de pêssego. Ambas as enzimas apresentaram comportamento Michaeliano, sendo que o gráfico da velocidade de hidrólise em função da concentração de sacarose foi confirmada pela linearidade da Lineweaver-Burk. A invertase de levedura de purê de pêssego mostrou-se menos específica, menor $\mathrm{K}_{\mathrm{m}}$, mas realiza a inversão da sacarose em temperaturas menores que a testemunha. Tal fato cinético é uma característica favorável para produção de açúcar invertido minimizando reações de escurecimento não enzimático. Finalmente, pode-se dizer que a $25^{\circ} \mathrm{C}$ e $\mathrm{pH}$ de 5 , ambas invertases isoladas do purê pêssego da cultivar Jubileu e do seu resíduo equivaleram-se em sua atividade, atigindo cerca de $50 \%$ da atividade da invertase de levedura de pão (testemunha). 
Tabela 6 - Análise de variância do modelo de Michaelis-Menten para invertase de levedura comercial e invertase de levedura de purê de pêssego cv. Jubileu.

\begin{tabular}{|c|c|c|c|c|c|c|}
\hline \multirow{3}{*}{$\begin{array}{c}\text { Fonte de variação } \\
\text { Enzima }\end{array}$} & \multicolumn{6}{|c|}{ Modelo: $V_{o}=\left(V_{\max } \times A_{o}\right) /\left(K_{m}+A_{o}\right)$} \\
\hline & \multicolumn{2}{|c|}{ Soma quadrática $(\mathrm{SQ})$} & \multicolumn{2}{|c|}{ Graus de liberdade (GL) } & \multicolumn{2}{|c|}{ Média quadrática (MQ) } \\
\hline & Levedura comercial & Levedura de pêssego & Levedura comercial & Levedura de pêssego & Levedura comercial & Levedura de pêssego \\
\hline Regressão & 1665.218025 & 186.725362 & 1 & 1 & 1665.218025 & 186.725362 \\
\hline Resíduo & 44.417924 & 5.546643 & 8 & 20 & 5.552241 & 0.277332 \\
\hline Total & 1709.63595 & 192.272006 & & & & \\
\hline $\mathrm{F}_{\mathrm{cal}}$ & 299.918206 & 673.291412 & & & & \\
\hline Ftab & 11,26 & 8.10 & & & & \\
\hline $\mathrm{R}^{2}$ & 0,9991 & 0,972 & & & & \\
\hline
\end{tabular}




\begin{abstract}
The fructofuranoside fructohydrolases (EC 3.2.2.26), formely called invertase or saccharase, catalyses the sucrose hydrolysis, producing na equimolar mixture of glucose and fructose called inverted sugar. This has higher edulcorant power and slow crystallization, causing an improvement in food texture and flavor. The invertase was extracted from yeasts isolated of Jubileu peach puree and its residues, that is widely cultivated in the South of Rio Grande do Sul, Brazil. The invertase that occur in commercial bread yeast was used with witness. The enzyme extracts were obtained using sodium bicarbonate extraction method. The optima conditions for reaction were studied using sucrose, as substrate, to $40 \mathrm{mM}$ for bread invertase and to $220 \mathrm{mM}$ for peach puree invertase. The glucose was determinate by colorimetry using DNS and protein by Biureto method. Optimum pH was 5-6 for both enzymes. The optimum temperature were $40-50^{\circ} \mathrm{C}$ and $20-30^{\circ} \mathrm{C}$ on invertases of bread yeasts and of peach puree yeasts, respectively. Both enzymes were affected by the heat denaturation, being bread invertase more thermostable. With the sucrose hydrolysis optimum conditions defined, the effect of the substratum concentration in both invertases activity was studied, as well as to determine the kinetic parameters of the sucrose hydrolysis. Both enzymes presented behavior Michaeliano. The Kinetic parameters were estimated by nonlinear regression, the $K_{m}$ values were $20 \mathrm{mM}$ e $180 \mathrm{mM}$, using sucrose as substrate, for invertase of bread yeast and invertase of peach puree yeast, respectively. For both invertases, the plot of the rate of sucrose hydrolysis versus sucrose concentration was confirmed by the linearity of the Lineweaver-Burk . Finally, there is an equivalence among the invertases activities of peach puree yeast and its residue at temperature of $25^{\circ} \mathrm{C}$ and $\mathrm{pH}$ of 5 .
\end{abstract}

Key-words: peach pure; yeasts; invertases; sucrose hydrolysis; inverted sugar.

\title{
Referências
}

ANDJELKOVIĆ, U.; PIĆURIĆ, S.; VUJČIĆ, Z. Purification and characterisation of Saccharomyces cerevisiae external invertase isoforms. Food Chemistry, n. 120, p 799-804, 2010. http://dx.doi.org/10.1016/j.foodchem.2009.11.013

BARBOSA, E. F.. Avaliação da atividade da invertase de Saccharomyces cerevisiae imobilizada em polianilina sobre o caldo de cana, 2009. 62 f. Dissertação (Mestrado em Biologia Molecular e Celular) - Programa de Pós Graduação em Biologia - Universidade Federal de Goiás.

BASCON, C. E.; GROENEWALD, J. H.; KOSSMANN, J.; CRONJÉ, C.; BAUER, R. Sugar an acid-related quality attributes and enzyme activities in strawberry fruits: Invertase is the main sucrose hydrolysing enzyme.. Food Chemistry, n. 121, p 1156-1162, 2010.

BORA, U.; KANNAN, K,; NAHAR, P. A simple method for functionalization of cellulose membrane for covalent immobilization of biomolecules. Journal Membrane Science, v. 250, p. 215-222, 2005. http://dx.doi.org/10.1016/j.memsci.2004.10.028

BRASIL. Ministério da Agicultura, Pecuária e Abastecimento - Instrução Normativa Normativa No 1 , de 7 de janeiro de 2000. Padrões de Identidade e qualidade para polpas de frutas. Diário Oficial da União. Brasil, 2000.

CABAJ, J.; SOLODUCHO, J.; JEDRYCHOWSKA, A.; ZAJAC, D. Biosensing invertase-based Langmuir-Shaefer films: Preparation and characteristic. Sensors and Actuators B: Chemical, n. 166-167, p 75-82, 2012. http://dx.doi.org/10.1016/j.snb.2011.12.034

CANTARELlA, L.; ALFANY, F.; CANTARELLA, M. 65. $\beta$-D-Fructofuranoside Fructohydrolase. In Handbook of food enzymology, eds Whitaker J.R., Voragen A.G.J., Wong D.W.S. (Marcel Dekker, New York). pp 787-804, 2003.

CANTIllano R. F. F.; ÁVIlla J. M. M.; PERAlBA M. C. R.; PIZZOLATO T. M.; TORALlES R. P.. 2012. Actividad antioxidante, compuestos fenólicos y ácido ascórbico de frutillas en dos sistemas de producción. Horticultura Brasileira, v.30, n.4, p. 620-626. out./dez., 2012.

COSTAGlioli, P.; MEILHOC, F.; JANATOVA, I.; KLEIN, R. e MASSON, J. Secretion of invertase from Schwanniomyces occidentalis. Biotechnology Letters, $\quad$ v. $\quad 19, \quad$ p. $\quad 623-627, \quad 1997$. http://dx.doi.org/10.1023/A:1018326512461

DANIEL, R. M ; PETERSON, M. E ; DANSON, M J ; PRICE, N. C. ; KELLY, S. M. ; MONK, C. R. ; WEINBERG, C. S. ; OUDSSHOOMn, M. L. ; LEE, C. K. The molecular basis of the effect of temperature on enzyme activity. The 
Biochemical journal, v. 425, n. 2, p.353-60, 2010. http://dx.doi.org/10.1042/BJ20091254

DANTAS, S. T. ; SARON, E. S. ; KIYATAKA, P. H. M. ; SOARES, B. C. ; GATTI, J. A. B. ; DANTAS, F. B. H. . Estudo da influência de danificações mecânicas provocadas em latas de pêssego em calda no desenvolvimento de corrosão interna. Brazilian Journal of Food Technology (Online), v. 15, n. 4, p. 343/351, 2012.

EMREGUL. E.; SUNGUR, S.; AKBULUT, U.. Polyacrylamide-gelatine carrier system used for invertase immobilization. Food Chemistry, 97, p. 591-597, 2006. http://dx.doi.org/10.1016/j.foodchem.2005.05.017

EMBRAPA - Empresa Brasileira de Pesquisa Agropecuária. Disponível em: http://sistemasdeproducao.cnptia.embrapa.br/FontesHTML/Pessego/PessegodeMesaRegiaoSerraGaucha/index.htm/ Acesso em: abril de 2012.

FONTANA, A.; GHOMMIDH, C.; GUIRAUD, J. e NAVARRO, J. Continuous alcoholic fermentation of sucrose using flocculating yeast - The limits of invertase activity. Biotechnology Letters, v. 14, n.2, p. 505-510, 1992. http://dx.doi.org/10.1007/BF01023176

FRANCHINI, E. R. Eficiência econômica da cadeia agroindustrual do pêssego indústria da região de Pelotas RS., 2008. 100 f. Monografia (Especialização em Agronegócio) -Departamento de Economia Rural e Extensão Universidade Federal do Paraná.

GACULA, M. C. Jr., SINGH, J. Statistical methods in food and consumer research. Orlando: Academic Press, Inc., 1984. 505 p.

GRACIDA-RODRÍGUEZ, J.; FAVELA-TORRES, E.; PRADO-BARRAGÁN, A.; HUERTAOCHOA, S. SAUCEDOCASTAÑEDA, G. Invertases. In: PANDEY, A.; WEBB, C.; SOCCOL, C.R.; LARROCHE, C. (Ed.) Enzyme Technology. New Delhi: Asiatech Publishers, 2005. p. 449-464.

GUIMARÃES , L. H. S.; TERENZI, H. F.; POLIZELI, M. L. T. M.; JORGE, J. A.. Prodution and characterization of a thermostable extracellular $\beta$-D-fructofuranosidase produced by Aspergillus ochraceus with agroindustrial residues as carbon sources. Enzime and Microbial Technology, n. 42, p 52-57, 2007.

HAYASHI, S.; MATSUZAKI, K.; TAKASAKI, Y.; UENO, H. e IMADA, K. Purification and properties of betafructofuranosidase from Aspergillus japonicus. World Journal of Microbiology \& Biotechnology, v. 8, n. 3, p.276279, 1992. http://dx.doi.org/10.1007/BF01201878

HOFFMANN, F. L.; GARCIA-CRUZ, C. H.; PAGNOCCA, F. C.; VINTURIM, T. M.; MANSOR, A. P. Microrganismos contaminantes de polpas de frutas. Ciência e Tecnologia de Alimentos, v. 17, n.1, p. 32-37, 1997.

IBGE. Instituto Brasileiro de Geografia e Estatística. Mapa Exploratório de Solos do Estado do Rio Grande do Sul. Porto Alegre, 2010.

LINEWEAVER, H.; BURK, D. The determination of enzyme dissociation constant. Journal of the American Chemical Society; v. 56, p. 658, 1934. http://dx.doi.org/10.1021/ja01318a036

LOPES, A. M. Termoinativação de polifenoloxidases e peroxidases e destruição térmica de leveduras em purê de pêssego da cultivar Jubileu. Pelotas, 2013. 101 f. Tese (Doutorado em Ciência e Tecnologia de Alimentos) Programa de Pós - Graduação em Ciência e Tecnologia de Alimentos - Universidade Federal de Pelotas.

MARTINS, C.R.; FARIAS, R.M. Produção de alimentos x desperdício: tipos, causas e como reduzir perdas na produção agrícola. Revista da Faculdade de Zootecnia, Veterinária e Agronomia, v.9, n.1, p.83-93, 2002.

MAUREL, K.; LEITE, G. B.; BONHOMME, M.; GUILliOT, A.; RAGEAU, R.; PÉTEL, G.; SAKR, S. Trophic control of bud break in peach (Prunus persica) trees: a possible role of hexoses. Tree Physiology, v. 24 , n. 5 p. 579 588, 2004. http://dx.doi.org/10.1093/treephys/24.5.579

MORIGUCHI, T.; SANADA, T.; YAMAKI, S. Properties of acid invertase purified from peach fruits. Phytochemistry, v. 30, n. 1, p 95-97, 1991. http://dx.doi.org/10.1016/0031-9422(91)84105-2

NOVAKI, L. Produção purificação e caracterização parcial da invertase obtida por fermentação em estado sólido de soja com Aspergillus casiellus. Toledo, 2009. 56 f. Dissertação (Mestrado em Processos Químicos e Bioquímicos) Programa de Pós-graduação em Engenharia Química - Universidade Estadual do Oeste do Paraná.

POTTER, G. W. H. Analysis of biological molecules: an introduction to principles, instrumentation and techniques. London: Champman e Hall, 1995, p. 41-89, 1995.

RAJ, L.; CHAUHAN, G. S.; AZMI, W.; AHN, J. -H.; MANUEL, J. Kinetics study of invertase covalently linked to a new functional nanogel. Bioresource Technology, n. 102, p 2177-2184, 2011. http://dx.doi.org/10.1016/j.biortech.2010.11.062

RODRIGUES, M. V. N.; RODRIGUES, R. A. F.; SERRA, G. E. ANDRIETTA, S. R.; FRANCO, T. Produção de xarope de açúcar invertido obtido por hidrólise heterogênea, através de planejamento experimental. Ciência e 
Tecnologia de Alimentos, v. 20, n.1, p.103-109, 2000. http://dx.doi.org/10.1590/S0101-20612000000100020

ROMERO-GÓMEZ, S.; Augur, C. e Vinegra-González, G. Invertase production by Aspergillus niger in submerged and solid-state fementation. Biotechnology Letter, v. 22, n. 15, p. 1255-1258, 2000. http://dx.doi.org/10.1023/A:1005659217932

SANTOS, A. F.. . Imobilização de invertase comercial e de Saccharomyces cerevisiae em sabugo de milho e bagaço de cana-de-açúcar. Araraquara, 2010. 92 f. Dissertação (Mestrado em Ciência dos Alimentos) - Programa de Pós-graduação em Alimentos e Nutrição - Universidade Estadual Paulista.

SANTOS, E. A.; OLIVEIRA, R. B.; MENDONÇA-HAGLER, L. C.; HAGLER, A. N. Yeasts associated with flowers and fruits from a semi-arid region of northeastern Brazil. Revista de Microbiologia, v. 1, n. 27, p. 33-40, 1996.

SEBRAE - Serviço de Apoio às Micro e Pequenas Empresas. Pelotas realiza $3^{\mathrm{a}}$ edição do Minuto do Pêssego. Disponível em: <http://sebraers.interjornal.com.br/noticia_pdf.

SOUSA, M. S. B.; VIEIRA, L. M.; SILVA, M. J. M.; LIMA, A. Caracterização nutricional e compostos antioxidantes em residuos de polpas de frutas tropicais. Ciência e Agrotecnologia, Lavras, v.35, n3, p. 554 - 559, maio/jun., 2011.

SOUZA, Tatiane. Produtividade e qualidade na fruticultura gaúcha. Revista Mensal do Conselho Regional de Engenharia, Arquitetura e Agronomia do Rio Grande do Sul, n 43, 2008, p. 12 - 16.

SWAISGOOD, H. E. Use of immobilized enzymes in the food industry. In Handbook of food enzymology, eds Whitaker J.R., Voragen A.G.J., Wong D.W.S. (Marcel Dekker, New York). pp 363-369, 2003.

TOMAS-BARBERAN, F. A.; GIL, M. I.; CREMIN, P.; WATERHOUSE, A. L.; HESS-PIERCE, B.; KADER, A. A. HPLC-DAD-ESIMS analysis of phenolic compounds in nectarines, peaches, and plums. Journal of Agricultural and Food Chemistry, v. 49, n.10, p. 4748-4760, 2001. http://dx.doi.org/10.1021/jf0104681

TORAllES, R. P.; MALGARIM, M. B.; VENDRUSCOLO, J. L.; CANTILLANO, R. F. F.; TREPTOW, R. O. Um estudo para compreender a preferência e aceitação de consumidores de purês de pêssegos brasileiros. Revista Brasileira de Fruticultura, Jaboticabal, v. 28, n. 3, p. 397-401, 2006.

TORALlES, R. T.; VENDRUSCOLO, J. L. Processamento do purê e néctar de pêssego. Comunicado Técnico 159 , Pelotas: Embrapa Clima Temperado, 2007.

VITOLO, M. Extração de invertase solúvel a partir de levedura de panificação (Saccharomyces cerevisiae). São Paulo, 1979. Dissertação (Mestrado em Ciências Farmacêuticas) - Universidade de São Paulo.

VUJČIĆ, Z.; MILORADOVIĆ, Z.; MILORADOVIĆ, A.; BOŽIĆ, N. Cell wall invertase immobilisation within gelatin gel. Food Chemistry, n. 126, p 236-240, 2011. http://dx.doi.org/10.1016/j.foodchem.2010.11.010

WHITAKER, J.R. 4. Enzyme-catalyzed reactions: experimental factors that affect rates . In Handbook of food enzymology, eds Whitaker J.R., Voragen A.G.J., Wong D.W.S. (Marcel Dekker, New York). pp 47-64, 2003.

Submetido em 20 jun. 2013; Aceito para publicação em 14 abr. 2014. 